\title{
Desenvolvimento do Hemomonitor com sistema de alertas para o paciente em uso de
}

\section{hemocomponentes}

\section{Development of the Hemomonitor with an alert system for the patient using blood componentes Desarrollo del Hemomonitor con sistema de alerta para el paciente utilizando componentes} sanguíneos

\section{Resumo}

Objetivo: Desenvolver o módulo de software Hemomonitor com sistema de alertas para monitoramento dos pacientes em uso de hemocomponentes. Metodologia: Trata-se de uma pesquisa aplicada realizada em um Hospital Universitário, cuja trajetória metodológica seguiu três etapas: 1) Caracterização do processo transfusional no local do estudo; 2) Atualização acerca dos softwares disponíveis sobre o tema por meio de uma revisão de literatura; 3) Desenvolvimento de software atualizado com base na literatura especializada. Resultados: Os fluxos de atividades desempenhadas foram deflagrados a partir da extração de dados multivariados dos sistemas, AGHUx e +Exames, 
utilizados pela instituição, para transformá-los em informações. Além disso, visando seu funcionamento, foi necessário parametrizar as alterações dos exames laboratoriais, certificar a prescrição do HC com a assinatura do médico responsável pelo paciente, construir um sequenciamento de solicitação de HC, permitir o compartilhamento das informações e interfaceamento entre os setores, padronizar os exames comprobatórios mediante à suspeita transfusional, identificar a amostra do paciente e da bolsa do HC de forma apropriada com a legislação, parametrizar os laudos para as provas de compatibilidade, permitir a rastreabilidade, parametrizar alterações dos sinais vitais para estabelecer vínculo temporal, definir as trilhas de auditoria, capacitar as equipes quanto à celeridade dos processos, eficiência e aproveitamento substancial dos recursos. Conclusão: A implementação do módulo Hemomonitor e a aplicação em uma unidade piloto permitiu observar que a sua utilização pode melhorar a monitorização e acompanhamento em tempo real dos pacientes em uso de $\mathrm{HC}$, auxiliando na antecipação de condutas eficazes para mitigação das RT.

Palavras-chave: Serviço de hemoterapia; Transfusão de componentes sanguíneos; Reação transfusional; Software; Sistemas de informação; Sistemas de apoio a decisões clínicas.

\begin{abstract}
Objective: To develop the Hemomonitor software module with an alert system for monitoring patients using blood components. Methodology: This is an applied research carried out in a University Hospital, whose methodological trajectory followed three steps: 1) Characterization of the transfusion process at the study site; 2) Update on available software on the subject through a literature review; 3) Development of updated software based on specialized literature. Results: The flows of activities performed were triggered from the extraction of multivariate data from the systems, AGHUx and +Exames, used by the institution, to transform them into information. In addition, aiming at its operation, it was necessary to parameterize the alterations of the laboratory tests, to certify the HC prescription with the signature of the doctor responsible for the patient, to build a $\mathrm{HC}$ request sequencing, to allow the sharing of information and interface between the sectors, to standardize the supporting exams upon suspicion of transfusion, identify the patient's sample and the $\mathrm{HC}$ bag in an appropriate way with the legislation, parameterize the reports for the compatibility tests, allow traceability, parameterize changes in vital signs to establish a temporal link, define the audit trails, train teams in terms of speed of processes, efficiency and substantial use of resources. Conclusion: The implementation of the Hemomonitor module and its application in a pilot unit made it possible to observe that its use can improve the real-time monitoring and follow-up of patients using $\mathrm{HC}$, helping to anticipate effective measures to mitigate TR.
\end{abstract}

Keywords: Hemotherapy service; Blood component transfusion; Transfusion reaction; Software; Information systems; Clinical decision support systems.

\begin{abstract}
Resumen
Objetivo: Desarrollar el módulo de software Hemomonitor con un sistema de alertas para el seguimiento de pacientes que utilizan componentes sanguíneos. Metodología: Se trata de una investigación aplicada realizada en un Hospital Universitario, cuya trayectoria metodológica siguió tres pasos: 1) Caracterización del proceso transfusional en el local de estudio; 2) Actualización sobre el software disponible sobre el tema a través de una revisión de la literatura; 3 ) Desarrollo de software actualizado basado en literatura especializada. Resultados: Los flujos de actividades realizadas se desencadenaron a partir de la extracción de datos multivariados de los sistemas, AGHUx y +Exames, utilizados por la institución, para transformarlos en información. Además, para su funcionamiento, fue necesario parametrizar las alteraciones de los exámenes de laboratorio, certificar la prescripción de HC con la firma del médico responsable del paciente, construir una secuencia de solicitud de HC, permitir compartir información y interfase entre los sectores, estandarizar los exámenes de soporte ante sospecha de transfusión, identificar la muestra del paciente y la bolsa de HC de forma adecuada a la legislación, parametrizar los informes para las pruebas de compatibilidad, permitir la trazabilidad, parametrizar cambios en los signos vitales para establecer un enlace temporal, definir las pistas de auditoría, capacitar a los equipos en términos de velocidad de los procesos, eficiencia y uso sustancial de los recursos. Conclusión: La implementación del módulo Hemomonitor y su aplicación en una unidad piloto permitió observar que su uso puede mejorar el monitoreo y seguimiento en tiempo real de los pacientes usuarios de HC, ayudando a anticipar medidas efectivas para mitigar la IT.
\end{abstract}

Palabras clave: Servicio de hemoterapia; Transfusión de componentes sanguíneos; Reacción a la transfusión; Software; Sistemas de información; Sistemas de apoyo a la decisión clínica.

\title{
1. Introdução
}

A transfusão de um produto sanguíneo é equiparada a um transplante de órgão sólido ou a um mini transplante, uma vez que exige rigor nos processos que englobam a transfusão desde a recomendação até o monitoramento do paciente (Chassé et al., 2015; Juffermans, 2020). Os eventos adversos provenientes da transfusão são tempo dependente, dose dependente e podem advir de forma simultânea, portanto, necessita de intervenção e de diagnóstico (Webert \& Hededle, 2017; Jug et al., 
2021). Logo, o processo transfusional requer avaliação, acompanhamento, monitoramento, análise de todas as etapas para estabelecer o nexo causal das RT e adotar as medidas de mitigação a fim de evitar recidivas (Hassan, 2021).

Conforme as diretrizes nacionais e internacionais, os elementos laboratoriais/ imagem, clínicos (sinais e sintomas, sinais vitais) e de interstício temporal são contundentes para definir as RT (ANVISA, 2015; IPST, 2016; ANSM, 2018; NHSN, 2018; ISBT, 2018; NHSN, 2021). A caracterização da Reação Transfusional (RT), permite a estratificação do risco e medidas de prevenção a partir da identificação imediata e manejo adequado (Kohorst et al., 2020). Outrossim, a rastreabilidade assume papel crucial para a otimização do processo transfusional devido a averiguação do controle de qualidade e identificação das possíveis falhas (ANSM, 2020).

A tecnologia de informação (TI) vem agregando e transformando os cuidados prestados centrados na segurança do paciente com a capacidade de compartilhamento de informações, com o aperfeiçoamento da comunicação, com a ampliação da documentação e até auxiliando na tomada de decisões pelos profissionais de saúde por meio de alertas e lembretes (Machado, 2016; Willians, 2019; Farokhzadian, 2020; Mueller, 2020; Sendelj, 2020).

A tomada de decisão depende da capacidade de coletar, organizar e exibir as informações imperiosas para subsidiar o diagnóstico do paciente, ou até mesmo de processos, quando se trata de gerenciamento de fatores de riscos. Nesse sentido, o suporte da TI proporciona a resolutividade dos profissionais de saúde com a utilização de critérios apropriados para determinada finalidade (por exemplo, celeridade de resultados), com a otimização da comunicação e da documentação, com a prevenção de erros de omissão, como em casos de resposta imediata frente a alterações laboratoriais de alto risco, além do mais, permite a distribuição de informações de forma uniforme e rastreamento de processos (Georgiou et al., 2021; Georgiou et al., 2019).

O gerenciamento desses dados exige um Sistema de Informação Hospitalar (SIH) e/ou Sistema de Apoio à Decisão (SAD) que contenham as informações para a tomada de decisão elevando o patamar de qualidade e segurança do paciente no setor da saúde (Bolcato et al., 2020; Dalal et al.2018); Tamfon et al., 2020). Baseado nisso, o objetivo do estudo foi desenvolver um módulo de software com sistema de alertas para monitorização de pacientes em uso de hemocomponentes (HC).

\section{Metodologia}

Trata-se de um estudo do tipo exploratório e descritivo com abordagem qualitativa caracterizado como pesquisa aplicada, pois teve como resultado o desenvolvimento de tecnologia de um software para monitorar pacientes em uso de hemocomponentes (HC) (Paranhos \& Paranhos, 2018). A produção tecnológica do tipo prototipagem foi utilizada para qualificar a assistência e avaliação registro, monitorizar o paciente em uso de HC, bem como, implantar medidas de prevenção após o diagnóstico da RT.

Esse estudo foi realizado em um Hospital Universitário Público de Aracaju - SE, Brasil. O presente artigo faz parte de um projeto maior intitulado: "Desenvolvimento de um protocolo integrado com sistema de alerta para o paciente em uso de hemocomponentes", aprovado pelo Comitê de Ética em Pesquisa da Faculdade de Enfermagem da Universidade Federal de Sergipe em junho de 2019, de acordo com o protocolo CAAE 33338720400005546 , o desenvolvimento do software ocorreu durante o período de 2019 e 2021. O projeto seguiu todos os preceitos éticos para investigações envolvendo seres humanos, especialmente os que estão descritos na Resolução n. 466/2012 (Brasil, 2012).

Para o desenvolvimento da proposta, foram necessárias percorrer algumas etapas: 1) Caracterização do processo transfusional no local do estudo; 2) Atualização acerca dos softwares disponíveis sobre o tema por meio de uma revisão de literatura; 3) Desenvolvimento de software atualizado com base na literatura especializada considerando os recursos relevantes à população alvo e a possibilidade das falhas elencadas na literatura e na prática laboral. 


\subsection{Ambiente da Pesquisa}

\subsubsection{Caracterização do HU-UFS}

O estudo foi realizado em um hospital de ensino da rede pública do Estado de Sergipe. O hospital contém 171 leitos, serve à população ao estado de Sergipe e municípios de estados limítrofes, atende as especialidades médicas e cirúrgicas. Dos 171 leitos, possui um tempo médio de internamento/ano de $18.92 \%$.

A pesquisa de campo foi planejada e implementada no Hospital Universitário de Sergipe, que atende exclusivamente pacientes do Sistema Único de Saúde (SUS). O projeto piloto foi realizado e operacionalizado na Unidade de Tratamento Intensivo (UTI) Geral no período de 2020 a 2021.

\subsubsection{Os sistemas do HU- UFS}

A utilização do AGHU nos Hospitais Universitários Federais iniciou em 2009, como parte integrante do Programa Nacional de Reestruturação dos Hospitais Universitários Federais (REHUF), do Ministério da Educação, destinado à reestruturação e revitalização dos hospitais das universidades federais. O objetivo do aplicativo é apoiar a padronização das práticas assistenciais e administrativas dos Hospitais Universitários Federais e permitir a criação de indicadores nacionais, o que facilitará a adoção de projetos de melhorias comuns para esses hospitais. O desenvolvimento e as atualizações do AGHU são realizados pela equipe de TI da Empresa Brasileira de Serviços Hospitalares (EBSERH). Atualmente, o sistema é utilizado em quarenta hospitais universitários da rede, entre outros.

A versão do aplicativo do AGHU mais recente é o AGHUx ou AGHU versão 10, que é constituído de módulos como: internamento, ambulatório, controle de pacientes, prescrições, evoluções dos profissionais da equipe interdisciplinar, entre outros, que facilitam a comunicação entre os servidores, assim como, os cuidados necessários para a manutenção da assistência prestada.

Nesses módulos, quaisquer registros como evoluções, controle de paciente, prescrições do paciente são realizados de forma on-line pelos profissionais de saúde e as informações ficam disponíveis para todos os envolvidos no atendimento, facilitando a uniformidade do cuidado, além de ser de fácil entendimento e evitar rasuras ou extravios dos registros. Nesse contexto, centraliza as informações necessárias em módulos para os profissionais de saúde, inibe a fragmentação da assistência, fortalece a comunicação segura e o cuidado oferecido. As atividades são registradas no sistema pelos profissionais de saúde e essas informações ficam disponíveis para os servidores envolvidos facilitando a eficácia da assistência prestada.

O sistema contém algumas limitações como a falta de funcionalidades de apoio à decisão, falta de preenchimento automático seguro, o uso de inteligência artificial para aumentar a produtividade e segurança nas ações, entre outros.

Outro sistema utilizado é o + Exames que é o sistema de gestão que armazena dados e gerencia os exames solicitados, realizados e laudados no HU. Esse sistema conta com os dados exportados do AGHUx para a identificação do paciente internado como nome completo, número de prontuário e data de nascimento (BRASIL, 2014). O sistema + Exames foi desenvolvido pela equipe do Setor de Gestão de Projetos e Tecnologia da Informação (SGPTI) do HU e permite acréscimos de informações do prescritor e padronização de exames como, por exemplo, exames a serem solicitados na admissão em pacientes na UTI.

\subsubsection{O processo transfusional no $\mathrm{HU}$}

A prescrição de hemocomponentes é realizada de forma manual e é composta por duas etapas: uma de solicitação na prescrição médica do paciente correspondente de forma manual e a outra por meio do preenchimento de uma via que será encaminhada para o hemocentro denominada de Solicitação Nominal de Hemocomponentes (SNH). Ambas as solicitações dependem da ausência de rasuras, da completude das informações e da legibilidade dos dados a serem informados pelo 
prescritor para maior clareza, entendimento e lisura do processo transfusional, tais como: identificadores do paciente, dose, volume, via de administração nas duas solicitações e, na via da SNH, deve-se registrar outros dados como: histórico transfusional, de alergias e obstétricos, tempo de infusão e da assinatura do prescritor com o número do Conselho Regional de Medicina.

No impresso da SNH, outro campo seria dos dados hematimétricos que podem não ser inseridos, pois trata-se de um campo optativo restando suposições e limitações em relação a avaliação do paciente e se a justificativa é condizente com os níveis de evidências vigentes.

Ademais, os dados fornecidos manualmente podem estar incompletos, com rasuras e apresentarem até ausência de informações, o que favorece inconsistências e erros assistenciais. Da mesma forma, esse processo artesanal se repete na identificação do paciente no tubo da amostra do paciente e da bolsa do HC. Sob essa perspectiva, esses dados podem ser transcritos de maneira incompleta ou incorreta, em quaisquer das etapas prescrição do HC, da análise laboratorial da Unidade Transfusional (UT) repercutirá na administração do HC. Portanto, mesmo com a análise dos testes de compatibilidade, a bolsa de hemocomponentes pode ser transfundida em um paciente não correspondente devido ao comprometimento da comunicação entre as equipes.

Vale ressaltar que o histórico transfusional da UT é realizada pela transcrição dos laudos dos testes de compatibilidade pelos responsáveis por esses testes em "cadernos de capa dura" com os dados do paciente e a equipe de enfermagem realiza o mesmo processo de registro em casos de coleta da amostra do paciente e da transfusão realizada. Assim sendo, denota a vulnerabildade do processo substanciado em anotações que podem conter incongruências, interpretações duvidosas por conta da caligrafia do profissional que registrou, rasuras, erros, abreviaturas e parcialidade das informações.

Outrossim, a ficha de monitorização do paciente também necessita da reprodução correta dos sinais vitais (temperatura, pulso, pressão arterial e frequência respiratória) pela equipe de enfermagem, a qual acontece apenas com a anotação à parte no prontuário. Por conseguinte, há uma limitação de informações por não estarem devidamente preenchidas ou parcialmente realizadas ou podem conter rasuras e serem ilegíveis. Outros dados que possam dispor na unidade como, por exemplo, na UTI que podem ser úteis no diagnóstico de RT não estão disponíveis nesse impresso, por exemplo: saturação de oxigênio (SpO2), Pressão Venosa Central (PVC), Débito Urinário (DU), entre outros, e que podem ser elementos imprescindíveis os quais possam subsidiar uma possível RT cardiopulmonar.

Além da administração, a monitorização fica a cargo da equipe de enfermagem na instituição e quaisquer manifestações clínicas que sugiram uma RT deve-se acionar o médico plantonista e a UT para proceder com o diagnóstico com os exames específicos a serem solicitados pelo médico plantonista (MP) ou do médico responsável pelo paciente. A notificação deve ser elaborada pelos enfermeiros assistenciais via Vigilância em Saúde e Gestão de Riscos Assistenciais Hospitalares (VIGIHOSP), porém, só prossegue para a investigação se houver o preenchimento da Ficha de Notificação e Investigação de Incidentes Transfusionais (FIT) por um médico conforme normativa da UT. Essa notificação será encaminhada para o setor do Serviço de Controle de Infecções Relacionadas à Assistência à Saúde (SCIRAS) / Unidade de Gestão Relacionados aos Aspectos Assistenciais (UGRA) e para a Agência Nacional de Vigilância Sanitária (ANVISA).

Ocorre a visita pós transfusional pelo enfermeiro da UT após as 24horas para análise da clínica do paciente posteriormente ao uso de HC. No entanto, essa avaliação a posteriori perde um dos pilares da imputabilidade que é o lapso temporal para as especificidades da RT, ou seja, a monitorização fica subordinado ao julgamento da equipe e ao reconhecimento de RT. Do mesmo modo que na vigência de uma RT e acionando a UT, caso o médico responsável solicite exames parciais ou não solicite os exames cabíveis compromete o diagnóstico da RT e submete o paciente à possibilidade de recidivas de RT. 
Os processos da instituição são documentados e descritos por meio de Protocolos e POP, incluindo o fluxograma descritos na notação Business Process Model and Notation (BPMN) e o uso da ferramenta Bizagi, a fim de esclarecer as responsabilidades de cada profissional, identificar cada atribuição e competências, otimizar os fluxos de trabalho e, consequentemente, potencializar a eficiência organizacional. À vista disso, as demandas foram distribuídas a partir da solicitação médica de HC seguido da definição dos exames de compatibilidade, do HC apropriado, da transfusão/descarte ou do estorno do HC, conforme apresentado na Figura 1.

Figura 1 - Ferramenta Bizagi.

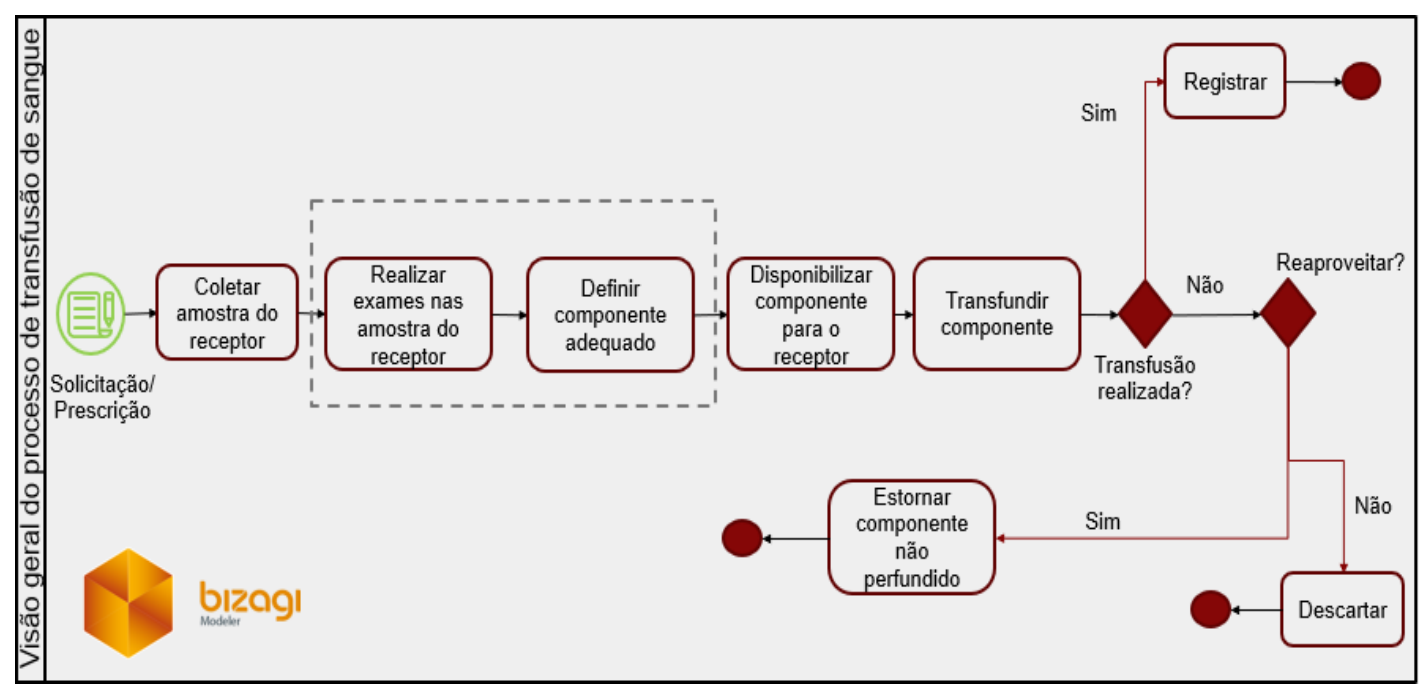

Fonte: Extraído dos processos da UT (2021).

\subsection{Prospecção tecnológica}

Com o objetivo de pesquisar soluções similares ao projeto proposto, foi realizada busca de patentes que pudessem se aproximar do escopo do produto Hemomonitor. Para essa finalidade foram designados como descritores os termos: ("Blood Transfusion" OR "Transfusion Reaction" OR "Blood Components" OR "Blood Products") AND ("Information Systems" OR "Health Information Systems" OR "Software" OR "Software Design").

A convergência entre as patentes e artigos se distribui entre as temáticas voltadas para o doador, controle de infusão do HC com regulador de fluxo, medidas de separação dos HC e alternativas de prevenção para redução de patógenos, não havendo compatibilidade entre as bases analisadas e o escopo do projeto, como demonstrado no Quadro 1.

Quadro 1 - Prospecção tecnológica em bases de patentes.

\begin{tabular}{|c|c|c|}
\hline Bases & Resultados & Concordância com o Projeto \\
\hline USPTO & 180 & Nada \\
\hline INPI & 32 & Nada \\
\hline EPO & 18 & Nada \\
\hline WIPO & 260 & 09 \\
\hline Free Patentes Online & 32325 & Nada $*$ \\
\hline Google Patentes & 12600 & Nada $*$ \\
\hline
\end{tabular}

Legenda: (*) Pesquisa realiza até a décima página. Fonte: Autores (2022).

No entanto, algumas funcionalidades similares ao Hemomonitor, foram encontradas, ainda que fracionada, contudo sem contemplar as mais relevantes em um único produto, como: gatilhos transfusionais, identificadores do paciente de acordo com as normativas que a legislação exige na prescrição médica de hemoterapia, na amostra e na bolsa do HC, justificativa para 
uso clínico do HC, compartilhamento das informações pertinentes do paciente para a unidade de lotação do paciente e da UT, sinais vitais, auditoria e relatórios gerenciais.

Em relação aos artigos, foram identificados 131 artigos com a busca supracitada no período de 1970 a 2021. Foram excluídos devido duplicidade três, após a triagem 123 artigos foram considerados elegíveis para leitura do título e resumo e apenas oito foram lidos na íntegra. Desses, todos pertenciam a base Pubmed. Por fim, um único artigo contemplou parcialmente os requisitos pré-definidos na temática escolhida e atendia a monitorização de sinais vitais e a metodologia empregada foi a observação direta.

\subsection{Desenvolvimento do software}

Como o objetivo principal do Hemomonitor é extrair dados das bases de dados dos sistemas AGHUx e +Exames para transformá-los em informações para melhor monitorização dos pacientes em uso de HC, se antecipar à suposta RT e dirimir lacunas que propiciem ineficiência e desperdício. A pesquisa foi baseada nas principais falhas que possam ocorrer no processo transfusional por Garcia (2020) e Maskens et al. (2014). Para compor um software voltado para o monitoramento da transfusão, foi avaliado um sistema de informação que abarcasse os conceitos e pilares que subsidiassem a visão geral da arquitetura do software desenvolvido. A potencialidade de falhas nas etapas do processo de hemotransfusão foi descrita no Quadro 2.

Quadro 2 - Potencialidade de falhas nas etapas do processo de hemotransfusão.

\begin{tabular}{|c|c|c|c|}
\hline \multirow[t]{8}{*}{ FASES } & Pré transfusão: & Ato transfusional & Pós transfusional \\
\hline & Indicação/ Justificativa & $\begin{array}{l}\text { Identificação do paciente e da } \\
\text { bolsa do HC }\end{array}$ & Comprovar a RT \\
\hline & Histórico transfusional & $\begin{array}{l}\text { Monitorização adequada de acordo } \\
\text { com sinais vitais e dos sinais e } \\
\text { sintomas }\end{array}$ & $\begin{array}{l}\text { Notificar adequadamente de acordo } \\
\text { com as manifestações clínicas, } \\
\text { exames comprobatórios e com lapso } \\
\text { temporal }\end{array}$ \\
\hline & $\begin{array}{l}\text { Informações incompletas na } \\
\text { prescrição de hemocomponentes que } \\
\text { pode culminar em erros da UT } \\
\text { (diagnóstico do paciente, peso, tipo } \\
\text { do HC) }\end{array}$ & Identificação das RT & $\begin{array}{l}\text { Implantar as medidas de mitigação } \\
\text { mediante diagnóstico formalizado no } \\
\text { prontuário do paciente }\end{array}$ \\
\hline & $\begin{array}{l}\text { Identificação do paciente, da amostra } \\
\text { e da bolsa do HC; }\end{array}$ & $\begin{array}{l}\text { Monitorização a cargo de apenas } \\
\text { um profissional }\end{array}$ & Auditorias consistentes \\
\hline & $\begin{array}{lll}\text { Histórico de testes } & \text { de } \\
\text { compatibilidade para a UT; } & \end{array}$ & Exames adequados para a RT & Desfecho \\
\hline & $\begin{array}{l}\text { Compartilhamento das informações } \\
\text { da unidade do paciente e da UT }\end{array}$ & $\begin{array}{l}\text { Conduta direcionada para a } \\
\text { suspeita transfusional }\end{array}$ & Relatórios \\
\hline & $\begin{array}{l}\text { Delay entre as fases de solicitação do } \\
\text { HC até a instalação do mesmo }\end{array}$ & Documentação & \\
\hline
\end{tabular}

Fonte: Autores (2022).

Nesse sentido, foram consideradas as variáveis que sustentam uma RT e objetivando os princípios da instituição, foi desenvolvido o modelo de causalidade das RT com base nas fontes (pessoas, organização e tecnologia) com suas potencialidades de soluções na organização para um SIH e de SAD, conforme ilustrado na Figura 2. 


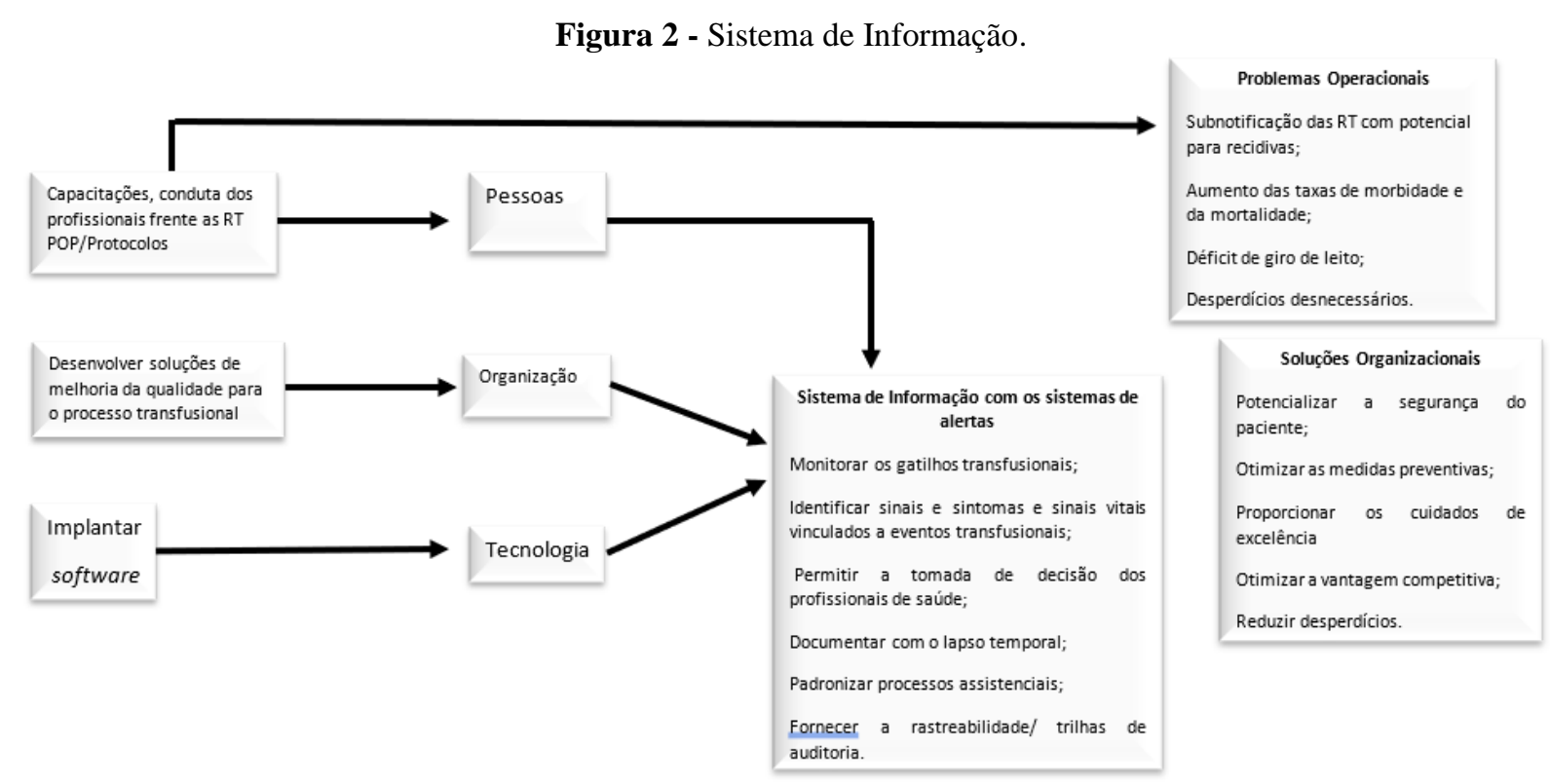

Fonte: Adaptado de Laudon e Laudon (2014).

A metodologia utilizada, adota as seguintes etapas: comunication: juntamente com as partes interessantes (stakeholders) estabelecem os requisitos e funções do software para a resolução do problema organizacional (monitorização das reações transfusionais); planing: por meio de map para definir as tarefas, os recursos necessários, e os produtos a serem produzidos com a previsão de prazos e cronograma; modeling: criação de esboço e modelos para atender os requisitos pré definidos; construction: desenvolvimento propriamente dito; deployment: envolve o emprego, a entrega e a retroalimentação o feedback stakeholders (Pressman, 2011; Pressman \& Maxim, 2020). A estrutura metodológica compreendeu as fases descritas a seguir:

2.3.1 Definição do projeto: nessa fase, foram elencadas as funcionalidades do Hemomonitor, a avaliação de metas, cronograma e o orçamento. Foi analisado o processo atual com as possibilidades de falhas e as alternativas para saná-las.

2.3.2 Critérios pré-determinados: os requisitos necessários nas etapas de transfusão foram compilados para assinalar as etapas do processo transfusional com base na Agência Nacional de Vigilância Sanitária (ANVISA), estudos e outros guidelines: NHSN, (2018-2021); Narayan et al. (2020), ISBT, (2018); Callum et al. (2017), ANSM, (2018), AZNZSBT (2019) e IPTS (2016). Para melhor compreensão do sequenciamento dessas etapas e de onde importar os dados, foi elaborado um fluxograma com as regras de negócio e com o desenho dos processos utilizando a notação BPMN por meio da ferramenta Bizagi. Dessa forma, pôde ser apurado e evidenciado os dados dos sistemas AGHUx e + Exames para transformá-los em informações pertinentes à equipe interdisciplinar por meio de alertas visualizados no Painel de Enfermagem no Módulo de Eventos.

2.3.3 Composição do sistema: O sistema consiste em atividades que compreendem um Sistema de Informação Hospitalar (SIH) e um Sistema de Apoio à Decisão da Gestão (SAD) que são compostas por entrada, processamento, saída, feedback ou retroalimentação. Os sistemas de informação em saúde propiciam avanços no processo de gestão e assistência ao paciente com avaliação clínica e epidemiológica (Nicanor, 2017). As atividades que compreendem um sistema de informação e que alimentam os SAD são compostas por entrada (coleta ou captura de dados crus na instituição), processamento (converte esses dados em resultados benéficos), saída (produção e transferência dessas informações em documentos, relatórios, gráficos), 
feedback ou retroalimentação (retorno dessas informações para prever eventos futuros, evitar problemas e correção de falhas na etapa de entrada). Essas atividades sustentaram o desenvolvimento do software com a definição de passos de execução, procedimentos e regras demonstradas na Figura 3 (Grant et al., 2021; Wazlavick, 2019).

Figura 3 - SIH e SAD do Hemomonitor.

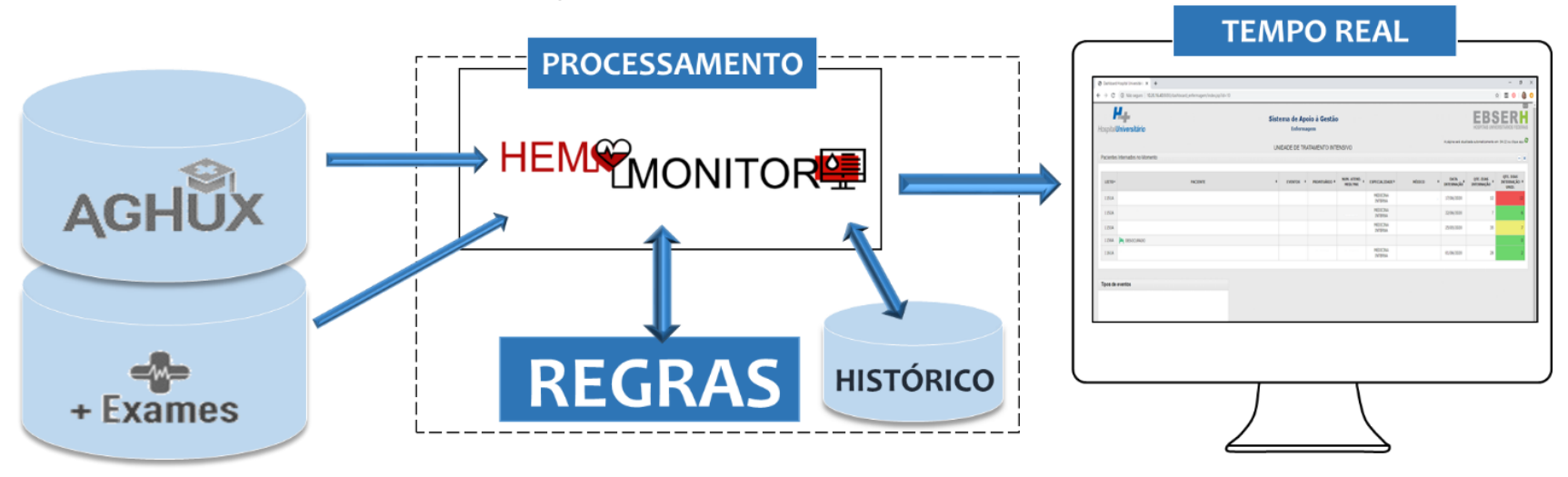

Fonte: Autores (2022).

2.3.4 Implantação do Módulo Hemomonitor: o software foi projetado para funcionar na intranet do hospital utilizando o Painel de Enfermagem para exibir os alertas e eventos. Foi implementado na UTI sendo possível visualizá-lo durante o processo laboral das atividades pelo Painel de Enfermagem ou quando logado em qualquer computador da instituição. O módulo Hemomonitor dispõe das informações por ícones pré-estabelecidos e a leitura dos dados são atualizadas a cada 3 minutos (Figura 4).

Figura 4 - Painel de Enfermagem.

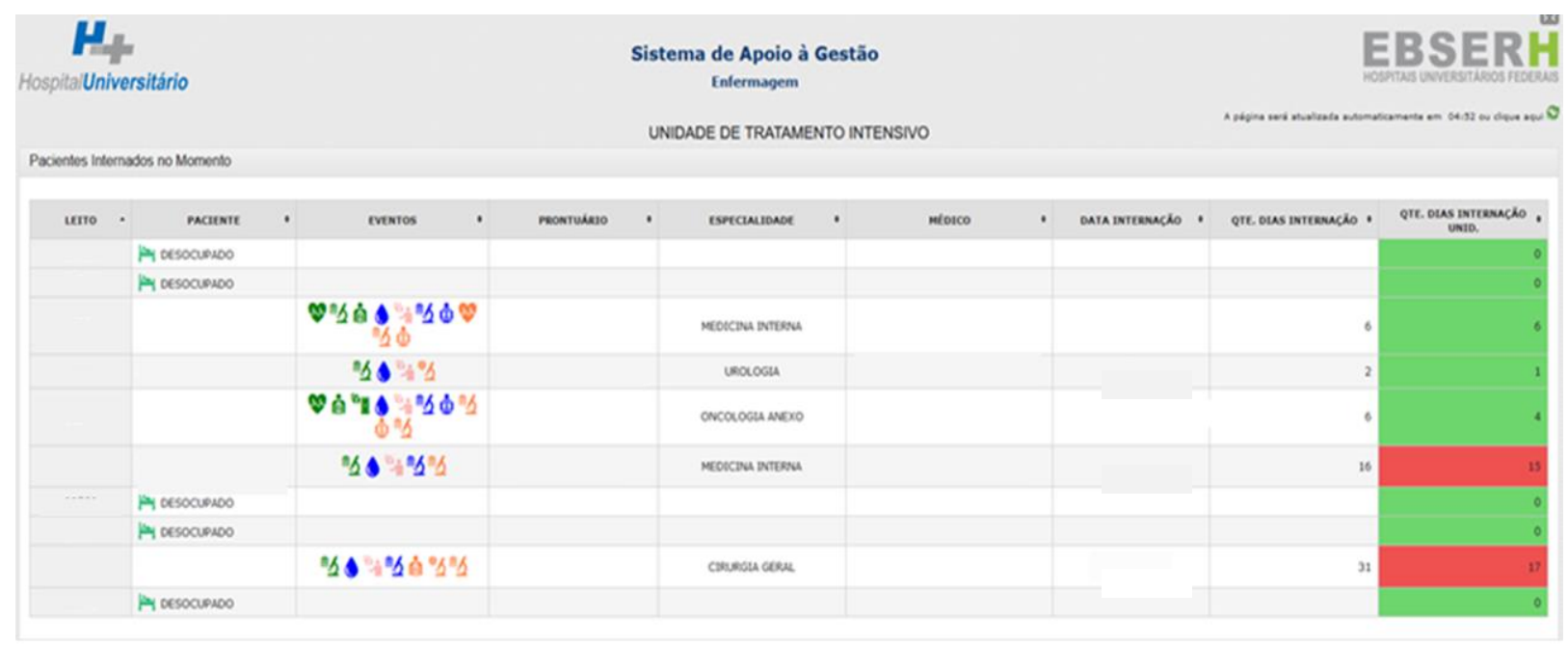

Fonte: Autores (2022).

\section{Resultados}

Os fluxos de atividades desempenhadas pelo Hemomonitor são deflagrados a partir da alteração dos resultados dos exames do sistema + Exames, no ato da assinatura do responsável técnico pela realização do resultado para hemoglobina, plaquetas e fibrinogênio. No intuito de ampliar a celeridade da indicação da transfusão e a prescrição do HC, foram organizados critérios com valores críticos ou gatilhos transfusionais parametrizados (triggers): hemoglobina <7,0 g/dl, 
plaquetas $<50.000 \mathrm{~mm} 3$, fibrinogênio $<100 \mathrm{mg} /$ dl sendo necessário que o Hemomonitor extraia esses dados do sistema + Exames e essa (s) alteração (ões) pode (m) acontecer com os pacientes internados no HU e será (ão) visualizado(s) no Painel de Enfermagem e/ou no computador logado da instituição com a gota rosa.

Dessa forma, o médico responsável pelo paciente prescreverá o HC no sistema AGHUx conforme a clínica do paciente específico e nele já contém todos os campos de identificadores do cliente e outros que devem ser assinalados, selecionados ou digitados que são de preenchimento obrigatório como o tipo do HC, quantidade por unidade ou por ml, frequência, aprazamento, quantidade de aplicações. Outras informações em campos não obrigatórios, tais como: transfusão realizada nos últimos três dias, paciente transplantado e tipo de transfusão: urgente. No campo de justificativa no sistema AGHUx para a finalidade da transfusão, os critérios foram ampliados de conforme as especificidades dos guidelines. Com a assinatura eletrônica do médico responsável ou da confirmação dos dados, será gerado uma gota laranja para o entendimento que existe uma "pendência de transfusão" para o paciente específico. A descrição do processo pode ser visualizada Figura 5.

Figura 5 - Fluxograma do sistema de alertas a partir dos gatilhos transfusionais.

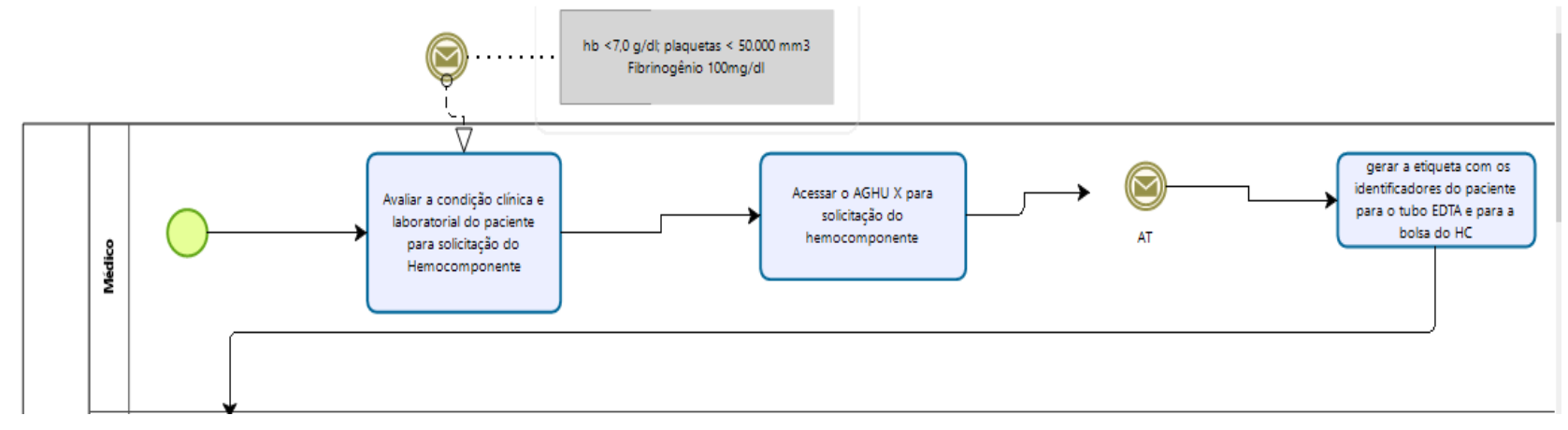

Fonte: Autores (2022).

Embora contenha dados essenciais na prescrição do AGHUx, estes não são visualizados na UT porque não ocorre o compartilhamento dessas informações da prescrição do HC solicitado para a UT. A impressão da prescrição do HC na unidade solicitante só consta o tipo de HC, quantidade, a via de administração e o aprazamento. Para visualizar os demais dados dessa prescrição no sistema AGHUx só poderá ser realizada por paciente, individualmente, o que inviabiliza auditorias da vigilância sanitária quanto ao rigor da documentação dos relatórios compilados de transfusão na instituição.

Sob esse aspecto, o compartilhamento de informações entre a UT e a unidade de origem dos dados relativos à transfusão foram adicionados no sistema +Exames com os campos necessários para a visualização da UT como tipo do HC (filtrado, irradiado, lavado), caráter da transfusão (urgente, programada, emergência, rotina), peso e altura do paciente, liberação para uso de heterogrupos. Por outro lado, o compartilhamento das informações acerca do diagnóstico do paciente, foi possível realizar com o acesso pelo sistema AGHUx pelos profissionais da UT e da unidade de origem da lotação do paciente.

Salienta-se que a UT assim como qualquer outra unidade pode visualizar as solicitações de HC de qualquer unidade com a solicitação do HC no AGHUx, com a gota laranja, que significa que existe uma prescrição de HC assinada eletronicamente pelo médico responsável do cliente.

Na UT, a informação da solicitação do HC será recepcionada pela equipe de enfermagem que gerará a etiqueta informatizada da amostra do paciente no tubo de EDTA correspondente com os identificadores do paciente extraídos do sistema AGHUX (nome do paciente completo, data de nascimento, número do prontuário), lotação (unidade de internação e leito) e data da coleta com o horário do sistema AGHUx, ou seja, todos os dados essenciais e determinados pela legislação para evitar erros ou rejeições da amostra pelo laboratório da UT. 
No laboratório da UT, o responsável pelos testes de compatibilidade receberá a amostra do paciente e com a solicitação em tela do sistema +Exames dará a sequência das atividades apresentado na Figura 6.

Figura 6 - Fluxograma do sequenciamento das práticas laboratoriais para o laboratório da UT.

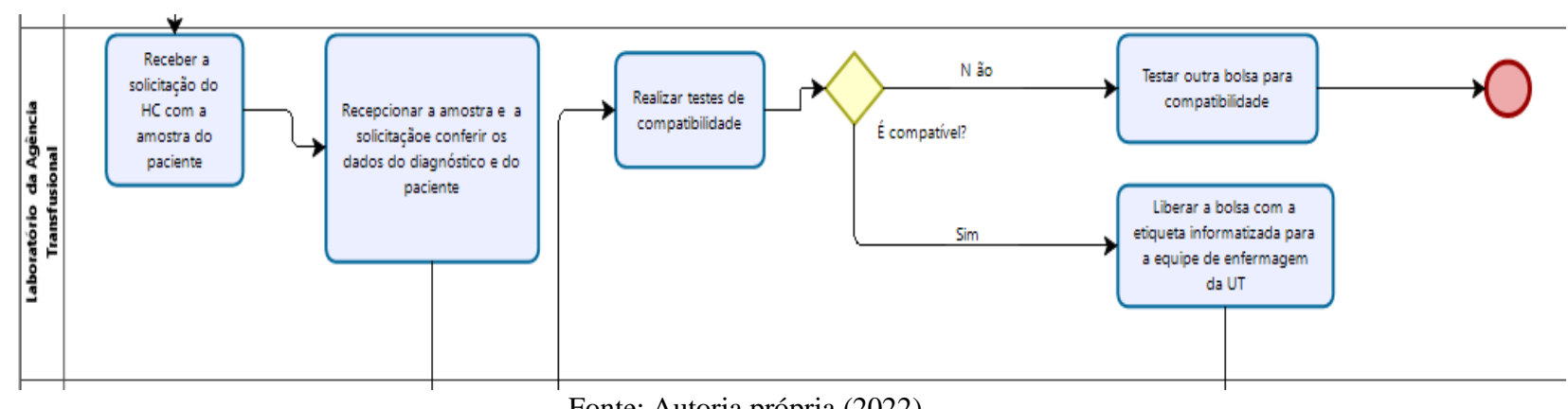

Fonte: Autoria própria (2022).

Os testes de compatibilidade estão padronizados para a UT. A etiqueta informatizada da bolsa do HC constará os resultados que são relevantes aos profissionais de saúde para os processos assistenciais e para a UT. Esses dados são pertinentes e reproduzem os resultados das provas de compatibilidade do paciente e da bolsa do HC. Esses resultados são extraídos como laudo no sistema + Exames e são impressos com as duas assinaturas eletrônicas: do responsável técnico pela realização dos referidos testes e do responsável técnico pela UT. Esses dados permitem maior rastreabilidade do doador e do receptor além de constar todos os requisitos impostos pela legislação de forma informatizada na bolsa do HC.

Para a monitorização dos sinais vitais, foram elencados os critérios para evento febril e evento hipotensivo com o lapso temporal específico. Com a ferramenta Bizagi, foi embasado os parâmetros da literatura vigente. Dessa forma, os eventos podem ser visualizados de acordo com a descrição a seguir no Painel de Enfermagem (Figura 7).

Figura 7 - Exemplos de evento febril e hipotensivo.

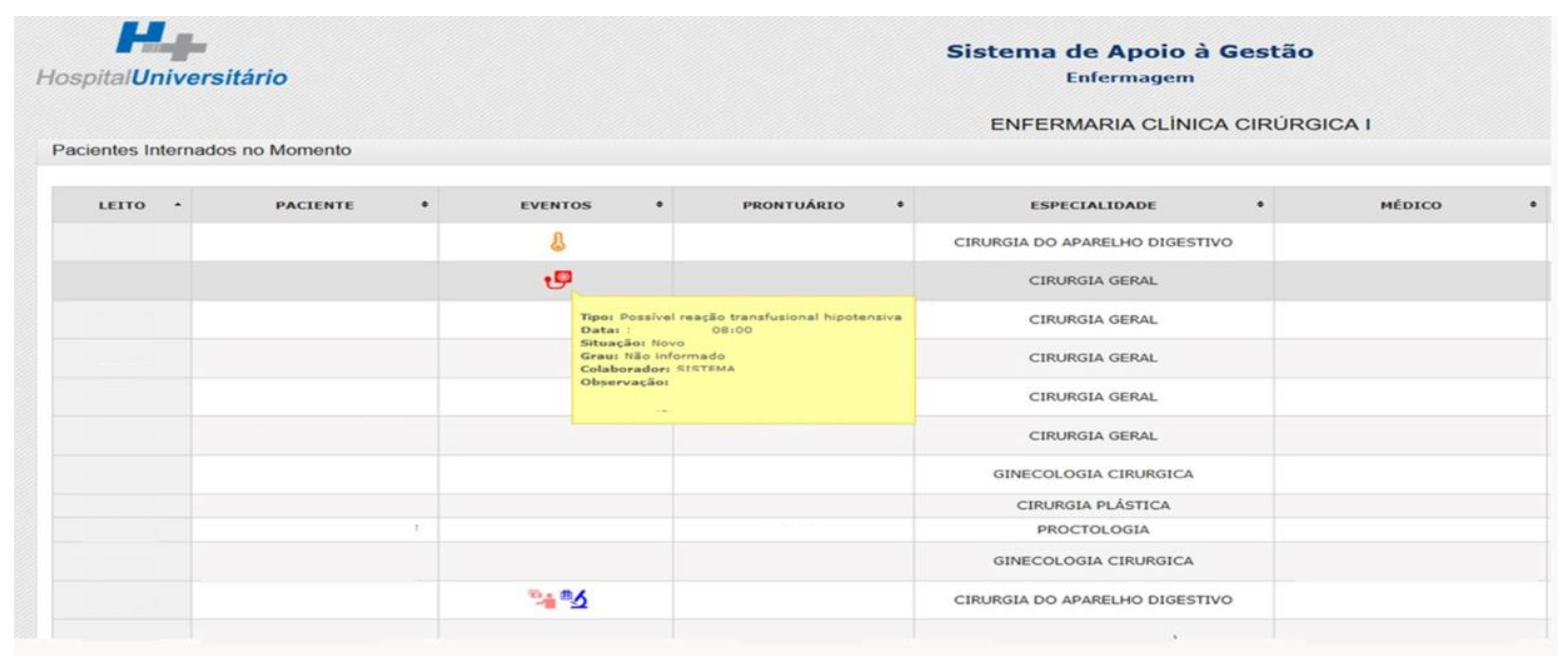

Fonte: Autores (2022).

Foi utilizado o módulo controle de paciente do sistema AGHUx, com os campos dos sinais vitais (temperatura, respiração, pulso, pressão arterial e, no caso da UTI, dispõe de saturação de Oxigênio (Spo2), Pressão Arterial Média (PAM), Pressão Venosa Central (PVC), medida do CO2 ao final da expiração pelo sensor de capnografia (ETCO2). Outros dados são o de Débito Urinário (DU), Balanço Hídrico (BH) em líquidos administrados, para que o módulo Hemomonitor filtre esses dados e transforme em informações disponibilizadas pelo Painel de Enfermagem ou logado em qualquer computador da instituição 
(Figuras 8 e 9). O profissional fará o preenchimento do controle dos sinais vitais de acordo com o preconizado pela UT com 15 minutos, 1 hora, 2 horas, 3 horas e 4 horas ou no término da infusão no próprio módulo de controle de pacientes.

Figura 8 - Modelo do controle de paciente contendo os sinais vitais pelo sistema AGHUx.

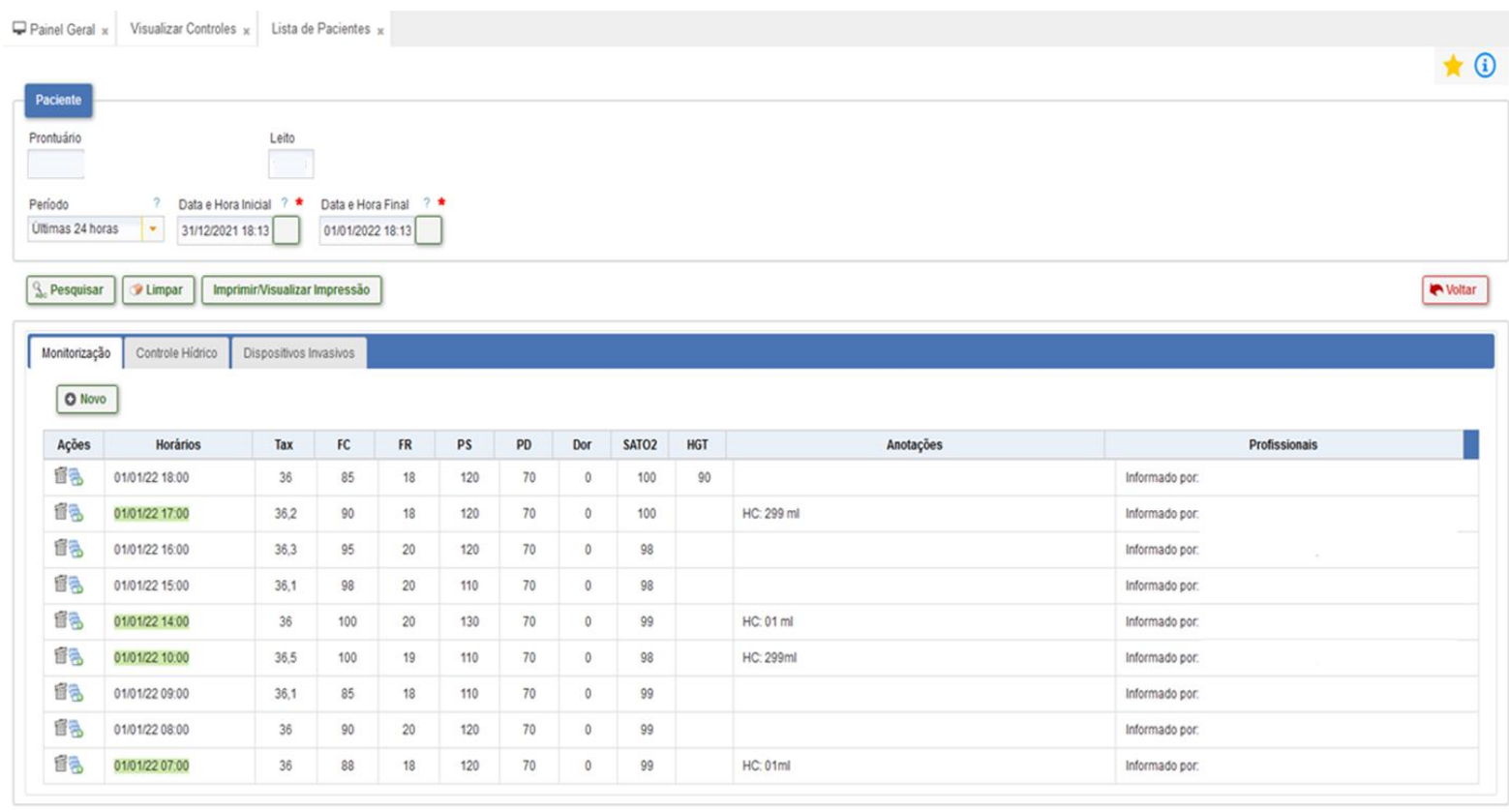

Fonte: AGHUx (2022).

Figura 9 - Modelo do controle de paciente com sistema AGHUx.

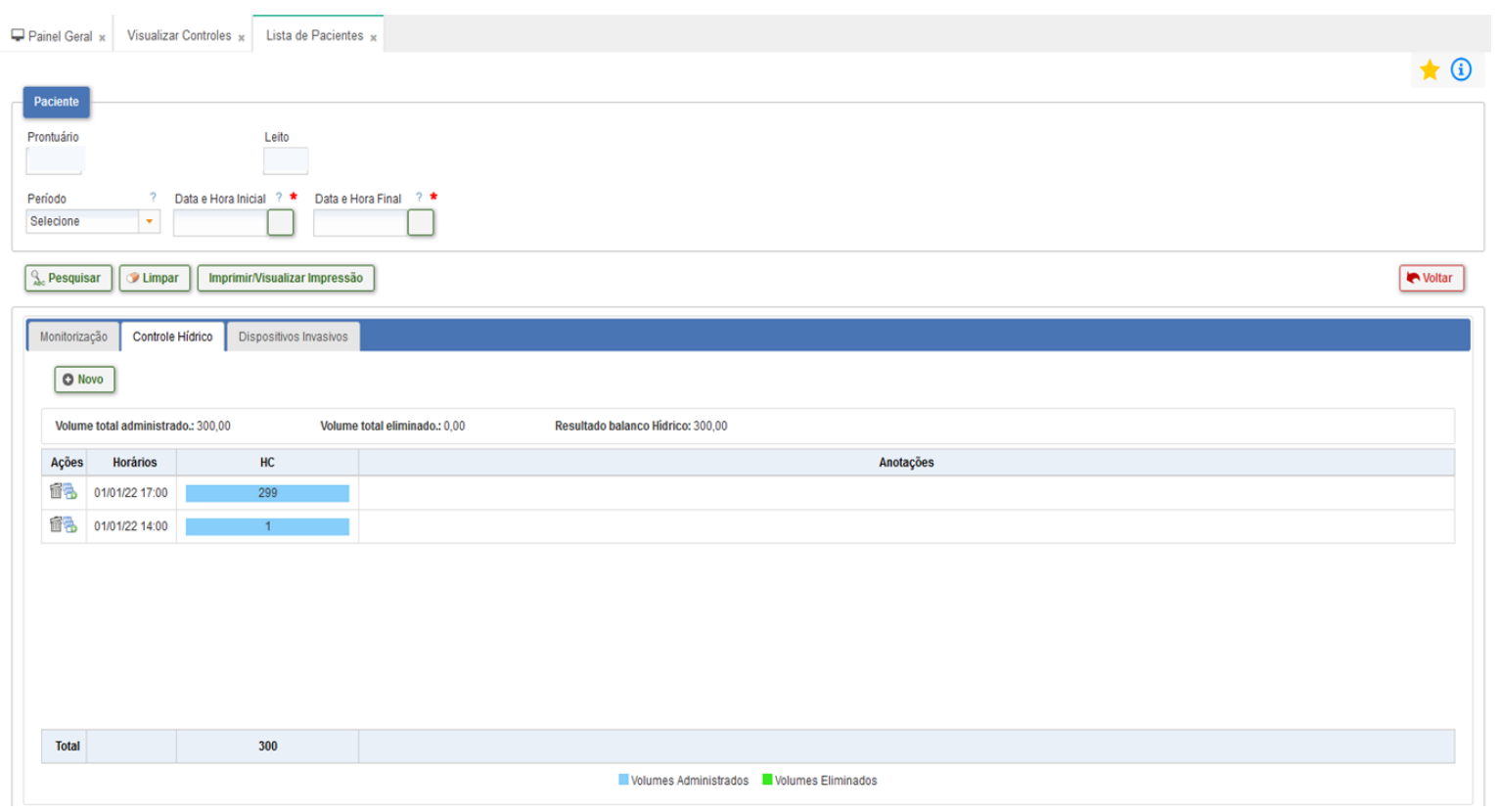

Fonte: AGHUx (2022).

Para o embasamento do lapso temporal, foi estipulada uma janela temporal de oito horas do término da transfusão (volume inicial seria de $1 \mathrm{ml}$ e o restante será preenchido ao final da transfusão no campo de HC no controle de pacientes) no mesmo controle que também é realizado o controle de sinais vitais. Com isso, após o término da transfusão o Hemomonitor emitirá um alerta a partir do preenchimento do valor residual no campo de HC do sistema AGHUx (diferente do valor 1ml) 
para que o profissional avalie se as alterações dos sinais vitais ou sinais e sintomas foram apresentadas conforme descrição desses pela ANVISA (2015).

Isso facilita a compreensão do período do início e fim da transfusão e a monitorização dos sinais vitais nesse intervalo. Esses dados numéricos inseridos no término da transfusão são visualizados pela equipe interdisciplinar no Painel de Enfermagem e/ou logado no computador da instituição com a gota vermelha. Desse modo, pode se verificar a taxa real de transfusões realmente realizadas e o desperdício caso sejam descartadas, parcialmente administradas ou estornadas. Isso facilita a realização de relatórios do tipo transfusões realizadas, HC estornados, HC que não foram infundidos e que são descartados em virtude da validade vencida ou suspensão da solicitação.

A fim de documentar ou descartar a suspeita da RT, faz-se imprescindível a realização de exames padronizados comprobatórios. Sendo assim, foi necessário parametrizar esses exames para a suspeita transfusional e excludentes de outros possíveis diagnósticos. Esses critérios foram elaborados pela pesquisadora principal juntamente com o responsável técnico da UT no sistema +Exames.

As trilhas de auditoria tornam-se relevantes em virtude da avaliação da agilidade e da relevância desse procedimento pelos profissionais. Além de preceder com acurácia e rapidez a detecção a partir dos exames laboratoriais à possibilidade de transfusão (representados pela gota rosa), pode analisar se a indicação foi assertiva, concisa e justificável diante dos níveis de evidência da literatura vigente, repercutindo indiretamente em desperdício e em exposição a eventos adversos desnecessários. A gota laranja é para assimilação da prescrição do HC e a equipe interdisciplinar precisa estar pronta para direcionar os cuidados prévios (por exemplo: acesso exclusivo, uso de diurético de alça prévio, uso de HC durante a hemodiálise, medidas de BH, DU e PVC). A gota azul retrata a disponibilidade do HC para uso no paciente podendo avaliar o intervalo entre o tempo de disponibilidade e de administração do HC. A gota vermelha servirá de interface para análise dos sinais vitais, do balanço hídrico e da evolução dos profissionais durante o lapso temporal para considerar as condutas utilizadas estavam condizentes com os guidelines. Ademais, analisará o desperdício de HC estornados ou infundidos de forma parcial (Figura 10).

Figura 10 - Padrão de cores das gotas.

\section{Padrão de Cores}

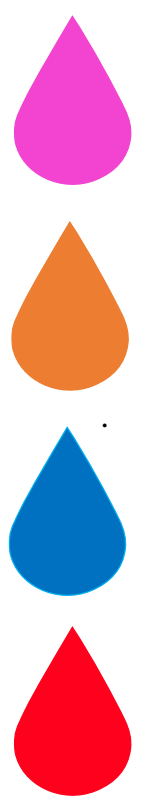

\section{Significado}

Após a liberação do resultado pelo responsável pelos resultados dos exames no sistema + Exames, os exames como hemoglobina, plaquetas e fibrinogênio que estiverem abaixo dos triggers estipulados, serão apresentados para a equipe assistencial incluindo a UT por meio desse alerta no Módulo de Eventos no Painel de Enfermagem e/ou logado na instituição;

Informação que houve uma prescrição de HC no sistema AGHUx para a UT;

Após os testes de compatibilidade, a bolsa de HC será liberada pela UT para uso na unidade solicitante;

Término da transfusão. 
Salienta-se que os processos das gotinhas são independentes e podem ser visualizados à medida que for ocorrendo à adesão ao sistema AGHUx. Por exemplo, só ocorreu a implantação da prescrição do HC na UTI, entretanto, a visualização das gotas rosa e azul podem ser visualizadas em qualquer unidade de internação e na UT a partir das alterações dos exames laboratoriais supracitados, assim como, após a impressão dos dados das provas de compatibilidade da bolsa do HC e do paciente uma vez que todos os pacientes transfundidos já fazem uso da bolsa informatizada do HC.

\section{Discussão}

Tendo em vista as fragilidades encontradas que dificultam a identificação e o reconhecimento de uma RT, foi visto que a informatização do processo transfusional em suas variadas etapas representa a instauração de um processo sinônimo de qualidade, segurança, monitoramento adequado e geração de indicadores com foco na prevenção. Dessa forma, segundo Alotaibi e Federico (2017), a tecnologia de informação em saúde tornou-se uma ferramenta de transformação da assistência, pois contribui para o fortalecimento da segurança do paciente, aperfeiçoando o atendimento, os resultados clínicos, a prática laboral e a rastreabilidade das informações.

Portanto, a deficiência ou as dificuldades encontradas no processo de rastreamento favorece à subnotificação, tornando perceptível à inexecução do diagnóstico de uma RT. Isso está de acordo com o que descreve Cagliano, Grimaldi e Rafele (2021) e Lemma et al. (2020), que a transfusão envolve um processo que abarca riscos logísticos e subprocessos interdependentes que comprometem a segurança do paciente, no entanto, os princípios da instituição podem dirimir as medidas de prevenção, potencializando as condições de trabalho com a geração de informações à beira leito e ferramentas que amparem à equipe. Sendo assim, o processo de monitoramento das RT propicia a validação da eficácia das medidas de segurança dos pacientes em uso de transfusão de acordo com Krakalic (2021).

Quando ocorrem as notificações, os registros ainda que de forma informatizada podem dificultar a caracterização da RT com a incompletude das informações fornecidas ou pela perda do vínculo temporal após as auditorias posteriores. Além do mais, o foco se torna o tratamento, sem direcionamento para a suspeita transfusional conforme estudo de Silva et al. (2021a). Em contrapartida, o software desenvolvido foi baseado nas fragilidades do processo transfusional na instituição para adicionar regras que promovam à celeridade a partir dos gatilhos transfusionais, sequenciamento das etapas com o rigor que cada uma requer e mapear a conduta que foi adotada.

Destarte, percebeu-se a necessidade de firmar o diagnóstico para garantir as medidas de mitigação na conjectura de um hospital público, tendo como base duas metas de segurança que são imprescindíveis (a identificação correta do paciente e a comunicação eficaz da equipe). A estratégia para dirimir a constatação de RT tem sido buscada de forma incessante pela literatura vigente em virtude das notificações (espontâneas ou compulsórias) realizadas e/ou busca ativa dos elementos chaves para a imputabilidade (quadro clínico, laboratorial/imagem e lapso temporal). Não obstante, como esses elementos reproduzem a conduta do profissional frente a uma RT, é pertinente retratar que são dependentes de identificação, reconhecimento da RT, assim como, do diagnóstico da RT para implantação de medidas de mitigação conforme estudo anterior de Silva et al. (2021b).

As principais lacunas que foram identificadas que podem condicionar a um erro ou a um near miss e que a TI pode interferir de forma positiva são: a identificação correta do paciente, a comunicação com a equipe, entre as equipes e com o paciente/família que foram direcionadas para: os identificadores do paciente na prescrição médica, na amostra para as provas de compatibilidade e na bolsa do HC que eram efetivados pelos profissionais pela técnica manual; indicação precisa com vínculo temporal (logo que constatada a necessidade de transfusão); meios para o diagnóstico contundente de RT, eventos associados à alteração de sinais vitais que podem voltar-se para uma RT e o histórico do processo transfusional com geração de relatórios (Silva et al., 2021a; Silva et al.,2021b). 
A prescrição médica informatizada busca os identificadores do paciente (nome completo, número do prontuário, data de nascimento - BRASIL, 2014) no sistema AGHUx. Nesse sentido, segundo Tsang et al. (2018), um sistema de solicitação de prescrições médicas informatizadas amplifica a fiabilidade das informações, aumenta a produtividade da equipe, reduz a carga de trabalho evitando a fadiga e padroniza o serviço. O prontuário informatizado permite alta disponibilidade dos dados e o processamento do Hemomonitor favorece que as informações sejam difundidas para a equipe interdisciplinar tanto da unidade transfusional como da unidade solicitante do $\mathrm{HC}$, contribuindo para a tomada de decisão com foco nos cuidados essenciais ao paciente conforme apontado por Oliveira e Favaretto (2020) e Silva et al. (2021b).

No presente estudo, a amostra do paciente com os seus identificadores passou a ser informatizada para evitar erros assistenciais. Essa prática já foi preconizada anteriormente com os estudos de Forest et al. (2017); Massey, Davenport e Kaufman (2020) e Allard et al (2021) em que se discute que uma amostra devidamente identificada pode reduzir em 51\% das taxas de rejeição, evitar atrasos e erros (requisição de teste não assinada, amostra e requisição não correspondem, discrepância no nome, discrepância de data de nascimento, amostra sem etiqueta, requisição sem etiqueta, número de registro médico incorreto), tornando um processo livre de falhas sob esse aspecto.

De acordo com estudos de Lee e Maslove (2015), Karim e Adil (2017) e Gehrie et al. (2021), o histórico dos testes imuno hematológicos pode assessorar a equipe do laboratório da UT com a verificação da presença de anticorpos detectados previamente que podem não ser identificados após um ano, uma vez que, o processo informatizado propicia que esses antecedentes sejam armazenados no sistema contribuindo para a não exposição do paciente a reações imunológicas com respostas cada vez mais exponenciais. Além do mais, essa prática evita testes desnecessários conforme estudo de Lee (2015).

Não obstante, Miller (2013) considerou que as auditorias que ocorrem pelo processo manual, têm como alvo o produto e não a identificação correta do paciente denotando a carência das práticas seguras por falta de rastreabilidade e de armazenamento de dados ou quando realizados podem ser comprometidos por erros de transcrição.

Desse modo, como garantia de segurança, as informações do laudo dos testes de compatibilidade compõem os dados da etiqueta da bolsa do HC pelo sistema informatizado com a assinatura do responsável pelos testes de compatibilidade e pelo responsável pela UT, conforme checklist de Osaka (2016). Por conseguinte, Rodrigues e Baptista (2018) salientaram a importância do armazenamento do de dados para compor o histórico, dessa forma, as informações pertinentes do histórico transfusional como de RT, testes de compatibilidade, uso de quimioterápicos, reações alérgicas, gestacional, como também da justificativa para o uso do $\mathrm{HC}$ serão retidos pelos dois bancos de dados dos sistemas AGHUx e + Exames.

Ademais, a associação de sinais vitais e sinais e sintomas também serve para direcionar a suspeita de RT e deve ser relatado e notificado em tempo real, a fim de embasar a definição, a imputabilidade e a gravidade da RT, conforme Yao et al. (2020). No caso de sinais e sintomas, a evolução do registro do profissional no sistema informatizado contidos no sistema do AGHUx evita inconsistências, não fica susceptível a rasuras e/ou ilegibilidade, favorecendo a análise do julgamento diante da suspeita transfusional.

Em relação ao módulo Hemomonitor, foram postulados parâmetros de sinais vitais conforme guidelines nacional e internacional (CDC/NHSN, (2018-2021); Narayan et al. (2020), ISBT, (2018); CBS, (2017), ANVISA, (2015) e IPST (2016). No caso de reação hipotensiva, foi associado a faixa etária do paciente e dados da pressão arterial no módulo de controle do paciente ambos contidos no sistema AGHUx com os parâmetros pré-determinados na literatura. Por exemplo, no caso de evento febril, os dados da temperatura são extraídos do sistema do AGHUx no módulo de controle do paciente.

$\mathrm{Na}$ etapa de documentação, o sistema AGHUx do módulo de evolução dos profissionais viabiliza a resolução das lacunas de registros, concentra as informações cabíveis do paciente para os profissionais de saúde e mantém a uniformidade da equipe, assim como, reverbera a comunicação segura e o cuidado prestado. Co isso, como já dito por Soares et al. (2021), os 
registros incompletos e ilegíveis nos prontuários comprometem a segurança do paciente. Além do que, para Orfão et al. (2017) e Omizzolo e Ramos (2021), quando todos os identificadores são respeitados, os déficits de comunicação podem ser evitados.

Segundo Sawadogo (2018), as práticas inadequadas e falsas interpretações descaracterizam a RT. Outrossim, registros incompletos e artesanais podem conferir uma subnotificação em até 10 vezes mais em relação ao método usual da monitorização de acordo com o exposto por Bernasinski (2013). Dessa maneira, um programa de hemovigilância, que busca a verdadeira incidência de RT, contribui para minimizar riscos e maximizar a formulação política. O sistema AGHUx, com a avaliação de cada profissional no módulo de evolução, permite a análise mais concreta a partir dos registros da equipe interdisciplinar. Sob esse óbice, todos os profissionais devem ser habilitados para atender pacientes com suspeita de uma RT e não ser monitorado apenas por um profissional da equipe conforme descrito por Silva et al. (2021a) e Polares (2018).

Adiciona-se que a comprovação da RT deve ser evidenciada com as manifestações clínicas, com os exames comprobatórios e com o período temporal (Narayan et al., 2020; NHSN 2018/2021; ANSM, 2018; IPST, 2016). Para isso, fazse necessário que o sistema de informações em tempo real confirme ou subsidie as RT, todavia, foi visto que a literatura carece de notificações, de ponderações corretas e noção sobre a temática, como indicado por Tanaka (2021).

Estudos como Ramoa e col. (2018) e Karim (2014), demonstram que o sistema de notificação não eletrônico dificulta a completude e a consistência dos dados, assim como, impacta de forma negativa no feedback e na qualidade de gestão da cadeia de hemovigilância. Nota-se que, a sistematização da assistência em saúde possibilita a operacionalização dos mais diversos processos, proporcionando ações controladas. Com o armazenamento de dados no Hemomonitor, pode-se gerar relatórios automáticos gerenciais e operacionais, permitindo a tomada de decisão conforme recomendado por Allard et al (2021). Em adição, exames comprobatórios também estão listados, de acordo com o protocolo específico, com o intuito de direcionar os profissionais às condições particulares relacionadas à especificidade da RT.

Outra vantagem é o potencial de subsidiar pesquisas fundamentadas em evidências a partir de um sistema informatizado e com auditorias direcionadas, conforme estudo de Allard et al (2021). Com isso, Mai e col. (2017), retratam que o sistema informatizado permite análise, monitoramento e planejamento, fomentando uma cultura de segurança do paciente pautada na avaliação dos dados colhidos, processados e disponibilizados para dar suporte a tomada de decisão em tempo real.

Para mais, a fim de adicionar a eficiência do andamento do processo e evitar atrasos desnecessários e sem suporte científico, foi compilado a necessidade de associar a indicação e a justificativa para a transfusão respaldados nos programas Patient Blood Management (PBM) e da inserção dos triggers incorporados ao Hemomonitor, como já indicado nos estudos de Butler e col. (2015) e Webert e Heddle (2017).

Sendo assim, as trilhas de auditoria criadas identificam falta de disponibilidade ou atraso/ delay na solicitação de um HC quando devidamente indicada, na dispensação do HC e na sua instalação podendo culminar no desfecho desfavorável do paciente frente à expectativa de internamento em relação à causa da hospitalização. De acordo com Narayan e col. (2020), os atrasos podem ser frutos de situações organizacionais/ estruturais e seus efeitos/ resultados poderão ser analisados em tempo real. Ainda, as trilhas de auditoria presentes no Hemomonitor indicarão o delay entre todas as etapas de transfusão, como recomendado, e poderão reduzir a realização de transfusões noturnas, uma prática que pode inferir em RT, segundo ANVISA (2015), Staples (2019) e Gonçalves (2018).

Narayann e col. (2020) descrevem a auditoria como elemento crucial para determinar a responsabilidade de onde os erros multifatoriais possam advir. Nesse contexto, o Hemomonitor contribui com o mapeamento da presteza dos profissionais no processo transfusional que podem resultar além dos retrocessos, da ineficiência e do desperdício no processo transfusional.

A rastreabilidade foi incentivada pela OMS embasada pelo ISBT 128 em 1994 com foco em obter o histórico do HC e avaliar as falhas no processo (Distler \& Ashford,2019). A rastreabilidade do software permite documentar o processo 
transfusional de maneira simplificada por meio das trilhas de auditoria propiciando a gestão do risco legal, antecipação nas etapas, a investigação do evento adverso, a análise da leitura da equipe quanto o reconhecimento da RT quanto ao diagnóstico e ao tratamento e apuração dos cuidados prévios que a equipe desempenhou como medidas de mitigação para amortizar as recidivas (Distler \& Ashford, 2019).

Com o Hemonitor, foram desenvolvidas as trilhas de auditoria com componentes chaves: gatilhos transfusionais que predispõem a necessidade de transfusão e a celeridade que deve ser imposta (gota rosa); prescrição médica no AGHUx permite agilidade frente à pendência de transfusão (gota laranja), disponibilidade do HC (gota azul), visto que podem ocorrer atrasos exagerados entre distâncias mínimas a horas de indisponibilidade ou não administração do HC, seja pela inexecução da UT ou pela ineficiência para a instalação do $\mathrm{HC}$ pela equipe assistencial, comprometendo à priorização, à validade e o incremento do HC; após o término da transfusão (gota vermelha), o Hemomonitor emitirá um alerta para a equipe para que sejam avaliados os embasamentos já descritos por guidelines em relação aos sinais vitais e sinais e sintomas configurados de acordo com o lapso temporal. Logo, os alertas encurtam o tempo para a tomada de decisões de acordo com Dalal e col. (2018).

Estudos de Marchesan et al. (2018) e Santos e Marin (2018), sugerem que sistemas de informação amparam a tomada de decisões, proporcionam avaliar a qualidade e a produtividade da assistência, incentivam ações corretivas e preventivas, e colocam a informação como ponto fulcral para o avanço tecnológico e competitividade entre as organizações. Dessa forma, o Hemomonitor se destaca por possibilitar o gerenciamento de risco de segurança do paciente, a fim de obter vantagens organizacionais e atingir elevados patamares de segurança, produtividade e inovação. Além do mais, ao analisar a informatização das UT, Vasudev e col. (2016) concluíram que esse recurso reduz a probabilidade de erros de execução, de transcrição dos testes de compatibilidade e de interpretação, ao revelar a verdadeira incidência de uma reação transfusional.

O módulo de software desenvolvido ainda se destaca em relação a informatização dessa prática uma vez que, em relação aos demais países, estamos atrasados em termos de sistema de informação hospitalar. Diversos sistemas informatizados existem há mais de vinte anos e, por isso, alguns artigos não são tão recentes e seriam redundantes em citar algo habitual na busca de dados nos dias atuais. Ao contrário de alguns países que utilizam um banco de dados como Statistical Package for the Social Sciences (SPSS) para suas pesquisas e outros ainda incipientes na questão de hemovigilância e com poucos recursos para otimizar a segurança no processo transfusional.

Outro ponto relevante é que a instituição detém os sistemas AGHUx, +Exames, SIH e SAD, que podem transformar dados em informações pertinentes por meio do módulo Hemomonitor, impactando na tomada de decisão dos profissionais e na assistência prestada. Esse fato demonstra que a TI pode além de auxiliar nos sistemas, intensificar as performances assistenciais e gerenciais necessárias para a celeridade das ações hospitalares.

Como fatores limitantes desse projeto, destacam -se à resistência da equipe em iniciar o processo só ocorrendo a operacionalização do AGHUx em meados de setembro 2021 pela equipe médica. A equipe de enfermagem encontra-se na fase de implantação e os demais profissionais ainda não iniciaram. Diante desse contexto associado a uma pandemia, não foi possível avaliar o impacto dessa tecnologia. Outra limitação seria a dependência do preenchimento dos profissionais e de diversas áreas no sistema AGHUx para a transparência das informações.

\section{Conclusão}

O desenvolvimento do Hemomonitor permitiu extrair dados multivariados de dois sistemas (AGHUx e +Exames) para transformá-los em informações. Esse módulo de software permite uma melhor monitorização e acompanhamento em tempo real dos pacientes em uso de HC, auxiliando a antecipação de condutas eficazes para mitigação das RT.

Salienta-se ainda que, o desenvolvimento de tal recurso representa uma alternativa sustentável e inteligente, uma vez que minimizará a ocorrência de extravios e perdas de informações que poderiam ocorrer nos prontuários físicos. 
Por fim, destaca-se que o desconhecimento de outra ferramenta que reúna todas as funcionalidades expostas, o que o módulo Hemomonitor uma inovação para o hospital face à informatização do processo transfusional, o qual permite que a prática ocorra em um sistema de linguagem atual e prática, objetivando o auxílio nas práticas laborais.

A fim de fomentar a segurança do paciente e a qualidade da cultura da gestão e dos profissionais, deve-se implantar novas metodologias e validar o módulo Hemomonitor para a verificação do seu impacto. Ademais, o Hemomitor precisará de ajustes do SIH e SAD à medida que novas pesquisas surjam e atualizações deverão ser implementadas.

Recomenda-se a realização das capacitações sobre o Hemomonitor para todas os profissionais do HU, visto que o software permita e ampare a segurança do processo transfusional na monitorização do paciente. Estudos voltados para essa temática ainda carecem de engajamento institucional, dos profissionais de saúde e do governo.

\section{Agradecimentos}

Gostaríamos de agradecer o apoio logístico do Hospital Universitário de Sergipe e de seus servidores, a rede EBSERH pelo incentivo a pesquisa, que permitiu o desenvolvimento do estudo e a todos os colaboradores que foram voluntários e disponibilizaram seu tempo para engrandecer a ciência.

\section{Referências}

Agence nationale de sécurité du medicament - ANSM. (2018). Sécurité du Médicament et des produits de Santé. ANSM. L'ANSM publie le rapport d'activité hémovigilance 2018. https://ansm.sante.fr/qui-sommes-nous/publications-institutionnelles/publications-2019.

Agência Nacional de Vigilância Sanitária - ANVISA. (2015). Marco Conceitual e Operacional de Hemovigilância: Guia para a Hemovigilância no Brasil. Brasília. https://www.gov.br/anvisa/pt-br/assuntos/fiscalizacao-e-monitoramento/hemovigilancia/publicacoes/marco-conceitual-e-operacional-dehemovigilancia-guia-para-a-hemovigilancia-no-brasil.pdf/view

Allard, S., Cort, J., Howell, C., Sherliker, L., Miflin, G., \& Toh, C. H. (2021). Transfusion 2024: A 5-year plan for clinical and laboratory transfusion in England. Transfusion Medicine.

Alotaibi, Y. K., \& Federico, F. (2017). The impact of health information technology on patient safety. Saudi Medical Journal, 38(12), 1173-1180. https://doi.org/10.15537/smj.2017.12.20631.

ANZSBT (2019). Guidelines for the administration of blood products. Australian \& New Zealand Society of Blood Transfusion Ltd. 3 Ed. https://anzsbt.org.au/wp-content/uploads/2018/06/ANZSBT_Guidelines_Administration_Blood_Products_3rdEd_Jan_2018.pdf>.

Bernasinski, M., Gette, S., Malinovsky, J. M., Babel, F. V., Charpentier, C., Audibert, G., ... \& Mertes, P. M. (2013). Les TRALI au CHU de Nancy: une incidence reconsidérée après l'application stricte des critères de Toronto. Transfusion clinique et biologique, 20(1), 40-45.

Bolcato, M., Russo, M., Trentino, K., Isbister, J., Rodriguez, D., \& Aprile, A. (2020). Patient blood management: The best approach to transfusion medicine risk management. Transfusion and Apheresis Science, 59(4), 102779.

Brasil- Ministério da Saúde (2014). Documento de referência para o Programa Nacional de Segurança do Paciente.https://bvsms.saude.gov.br/bvs/publicacoes/documento_referencia_programa_nacional_seguranca.pdf

Cagliano, A. C., Grimaldi, S., \& Rafele, C. (2021). A structured approach to analyse logistics risks in the blood transfusion process. Journal of Healthcare Risk Management.

Canadian Blood Services - CBS. (2017). System Progress Reports. https://www.blood.ca/en/about-us/publications-and-reports/system-progress-reports.

Center for Disease Control/National Healthcare Safety Network - CDC/NHSN. (2021). National Healthcare Safety Network biovigilance component hemovigilance module surveillance Protocol v2.6. The United States of America. https://www.cdc.gov/nhsn/pdfs/biovigilance/bv-hv-protocol-current.pdf.

Center for Disease Control/National Healthcare Safety Network - CDC/NHSN. (2018). NHSN Biovigilance Component, Hemovigilance Module Protocol. The United States of America. https://www.cdc.gov/nhsn/acute-care-hospital/bio-hemo/index.html.

Chasse, M., McIntyre, L., Tinmouth, A., Acker, J., English, S. W., Knoll, G., \& Fergusson, D. A. (2015). Clinical effects of blood donor characteristics in transfusion recipients: protocol of a framework to study the blood donor-recipient continuum. BMJ Open, 5(1), e007412-e007412. https://doi.org/10.1136/bmjopen-2014-007412.

Dalal, A. K., Schaffer, A., Gershanik, E. F., Papanna, R., Eibensteiner, K., Nolido, N. V., ... \& Schnipper, J. L. (2018). The impact of automated notification on follow-up of actionable tests pending at discharge: a cluster-randomized controlled trial. Journal of general internal medicine, 33(7), 1043-1051.

De Alcântara Oliveira, S., \& Favaretto, F. (2021). Qualidade da Informação do Prontuário Eletrônico do Paciente no Processo de Apoio à Decisão Clínica. Journal of Health Informatics, 13(1).

Distler, P., \& Ashford, P. (2019). Twenty-five years later: has ISBT 128 fulfilled its promise? Transfusion, 59(12), 3776-3782. 
Farokhzadian, J., Khajouei, R., Hasman, A., \& Ahmadian, L. (2020). Nurses' experiences and viewpoints about the benefits of adopting information technology in health care: a qualitative study in Iran. BMC Medical Informatics and Decision Making, 20(1), 1-12.

Forest, S. K., Shirazi, M., Wu-Gall, C., \& Stotler, B. A. (2017). The impact of an electronic ordering system on blood bank specimen rejection rates. American journal of clinical pathology, 147(1), 105-109.

Garcia, J. (2020). Segurança do processo transfusional em pacientes cirúrgicos de um hospital público de ensino do interior de Minas Gerais. Dissertação do Programa de Pós-Graduação em Medicina Tropical e Infectologia. Minas Gerais: Universidade Federal do Triângulo Mineiro.

Gehrie, E. A., Savani, B. N., \& Booth, G. S. (2021). Risk factors for hemolytic transfusion reactions resulting from ABO and minor red cell antigen incompatibility: From mislabeled samples to stem cell transplant and sickle cell disease. Blood reviews, 45, 100719.

Georgiou, A., Li, J., Hardie, R. A., Wabe, N., Horvath, A. R., Post, J. J., Eigenstetter, A., Lindeman, R., Lam, Q., Badrick, T., \& Pearce, C. (2021). Diagnostic Informatics-The Role of Digital Health in Diagnostic Stewardship and the Achievement of Excellence, Safety, and Value. Frontiers in digital health, 3, 659652 .

Georgiou, A., Li, J., Thomas, J., Dahm, M. R., \& Westbrook, J. I. (2019). The impact of health information technology on the management and follow-up of test results - a systematic review. Journal of the American Medical Informatics Association: JAMIA, 26(7), 678-688.

Gonçalves, L. A. L., Pinto, A. C. S. (2018). Hemovigilância - investigação de subnotificação de reação transfusional imediata. Dissertação do Programa de Mestrado em Ciências.

Grant, A. M., Wright, F. A., \& O'Brien, T. A. (2021). Rationalised premedication practice for blood product transfusions: A single-centre quality initiative. Journal of paediatrics and child health.

Hasan, M., Siddiqui, I. A., Qamar, Z., \& Hayat, A. (2021). An audit of transfusion reaction monitoring and reporting at a cancer hospital in Pakistan-a step towards hemovigilance. Journal of the Pakistan Medical Association, 71(2), 699-703.

Instituto Português do Sangue e da Transplantação - IPST. (2016). Base de dados do Instituto Português do Sangue e da Transplantação. https://www.ine.pt/xportal/xmain?xpid=INE\&xpgid=ine_indicadores\&indOcorrCod=0006132\&contexto=bd\&selTab=tab2

International Society of Blood Transfusion/International Haemovigilance Network, ISBT/IHN. (2019). Definição revisada de caso de vigilância internacional de sobrecarga circulatória associada à transfusão: uma classificação estudo de validação de contrato. https://www.isbtweb.org

Juffermans, N. P., Aubron, C., Duranteau, J., Vlaar, A. P., Kor, D. J., Muszynski, J. A., ... \& Vincent, J. L. (2020). Transfusion in the mechanically ventilated patient. Intensive care medicine, 1-8.

Jug, R., Anani, W., \& Callum, J. (2021). A possible case of recipient anti-neutrophil and anti-human leukocyte antigen antibody-mediated fatal reverse transfusion-related acute lung injury. Transfusion, 61(4), 1336-1340.

Karim, F., \& Adil, S. N. (2017). Eliminating wrong blood transfusions-recent advances. Journal of Pakistan Medical Association, 67(5), 659-660.

Karim, F., Moiz, B., Shamsuddin, N., Naz, S., \& Khurshid, M. (2014). Root cause analysis of non-infectious transfusion complications and the lessons learnt. Transfusion and Apheresis Science, 50(1), 111-117.

Kohorst, M. A., Khazal, S. J., Tewari, P., Petropoulos, D., Mescher, B., Wang, J., ... \& Kelley, J. M. (2020). Transfusion reactions in pediatric and adolescent young adult haematology oncology and immune effector cell patients. EClinicalMedicine, 26, 100514.

Kracalik, I., Mowla, S., Basavaraju, S. V., \& Sapiano, M. R. (2021). Transfusion-related adverse reactions: Data from the National Healthcare Safety Network Hemovigilance Module_-United States, 2013-2018. Transfusion, 61(5), 1424-1434.

Laudon, K. C., Laudon, J. P., \& Marques, A. S. (2014). Sistemas de informação gerenciai. Pearson Educación.

Lee, J., \& Maslove, D. M. (2015). Using information theory to identify redundancy in common laboratory tests in the intensive care unit. BMC medical informatics and decision making, 15(1), 1-8.

Lee, T. Y., Sun, G. T., Kou, L. T., \& Yeh, M. L. (2017). The use of information technology to enhance patient safety and nursing efficiency. Technology and health care : official journal of the European Society for Engineering and Medicine, 25(5), 917-928.

Miller, K., Akers, C., Magrin, G., Whitehead, S., \& Davis, A. K. (2013). Piloting the use of 2D barcode and patient safety-software in an Australian tertiary hospital setting. Vox Sanguinis, 105(2), 159-166.

Lemma, S., Janson, A., Persson, L. Å., Wickremasinghe, D., \& Källestål, C. (2020). Improving quality and use of routine health information system data in low-and middle-income countries: A scoping review. PloS one, 15(10), e0239683.

Mai, S., Guimarães, C. F., Silva, J. M., \& Hinkel, J. H. S. (2017). O uso das tecnologias na democratização da informação em saúde. Revista de Gestão em Sistemas de Saúde, 6(3), 210-218.

Marchesan Neto, R. (2018). Desenvolvimento de um protótipo de sistema informatizado de controle para gestão da saúde. Trabalho de conclusão de curso (TCC) em Ciências da Computação.

Maskens, C., Downie, H., Wendt, A., Lima, A., Merkley, L., Lin, Y., \& Callum, J. (2014). Hospital-based transfusion error tracking from 2005 to 2010: identifying the key errors threatening patient transfusion safety. Transfusion, 54(1), 66-73.

Massey, E. J., Davenport, R. D., \& Kaufman, R. M. (2017). Haemolytic transfusion reactions. Practical Transfusion Medicine, 81-96. 
Mueller, M. M., Van Remoortel, H., Meybohm, P., Aranko, K., Aubron, C., Burger, R., ... \& Seifried, E. (2019). Patient blood management: recommendations from the 2018 Frankfurt Consensus Conference. Jama, 321(10), 983-997.

Mueller, T. (2020). Information technology and eHealth to improve patient safety. Der Internist.

Nicanor, J. S. (2017). Desenvolvimento e aplicação de um programa computacional para armazenamento de dados e seguimento de pacientes em hemoterapia. Dissertação do Programa de Mestrado em Hemoterapia. São Paulo: Universidade de São Paulo.

Ohno-Machado, L. (2017). Using health information technology for clinical decision support and predictive analytics. Journal of the American Medical Informatics Association, 24(1), 1-1.

Ohsaka, A., Kato, H., Kino, S., Kawabata, K., Kitazawa, J., Sugimoto, T., ... \& Handa, M. (2016). Recommendations for the electronic pre-transfusion check at the bedside. Blood Transfusion, 14(5), 419.

Omizzolo, J. E., \& Ramos, K. S. (2021). Registros de enfermagem: um instrumento para a qualidade da assistência. Inova Saúde, 11(1), 114-129.

Orfão, N. H., Crepaldi, N. Y., Brunello, M. E. F., Andrade, R. L. D. P., Monroe, A. A., Ruffino-Netto, A., \& Villa, T. C. S. (2017). Coordenação da assistência à tuberculose: registro de dados e a implementação de um sistema informatizado. Ciência \& Saúde Coletiva, 22, $1969-1977$.

Paranhos, L. R. L.; Paranhos, P. J. R. (2018). Metodologia da pesquisa aplicada à tecnologia. SENAI-SP Editora.

Pressman, R. S. (2009). Engenharia de Software. 7 ed.,Amgh Editora.

Pressman, R. S.; Maxim, B. R. (2020). Software engineering: a practitioner's approach. 9 ed ed. United States of America: McGraw-Hill Education.

Ramoa, A., Condeço, J., Escoval, M. A., Faber, J. C., Fdez-Riverola, F., \& Lourenço, A. (2018). The Evolving Role of Information Technology in Haemovigilance Systems. Journal of healthcare engineering.

Santos, M. C. D., \& Marin, H. D. F. (2018). Análise do uso de um sistema informatizado por gestores hospitalares. Acta Paulista de Enfermagem, 31, 1-6. Sawadogo, S., Nebie, K., Millogo, T., Sontie, S., Nana, A., Dahourou, H., ... \& Deneys, V. (2018). Traceability of blood transfusions and reporting of adverse reactions in developing countries: a six-year postpilot phase experience in Burkina Faso. Advances in hematology, 2018.

Šendelj R. (2020). Information Technology and Information Management in Healthcare. Studies in health technology and informatics, 274, $139-158$.

Silva, A. B., de Oliveira, A. A., Silva, J. D. O. M., Santos, G. K. D. B. B., Esteves, R. B., \& da Silva, Â. M. (2021a). Caracterização epidemiológica das reações transfusionais imediatas em um hospital público de ensino. Research, Society and Development, 10(9), e5110916635-e5110916635.

Silva, A. B., Oliveira, A. A. de, Silva, J. de O. M., Santos , G. K. de B. B. ., Esteves, R. B., \& Silva, Ângela M. da . (2021b). Proposal of a standard operating procedure for the mitigation of immediate transfusion reactions in a university hospital. Research, Society and Development, 10(11), e32101119257. https://doi.org/10.33448/rsd-v10i11.19257

Soares, F. M. M., Cruz, R. C., Almeida, R. D., da Silva Camilo, J. K., \& Scopacasa, L. F. (2019). Avaliação Dos Registros De Enfermagem Acerca Da Reação Transfusional. Revista Enfermagem Atual In Derme, 90(28).

Staples, S., Staves, J., Davies, J., Polley, N., Boyd, J. S., Lukas, M., ... \& Murphy, M. F. (2019). Electronic remote blood issue supports efficient and timely supply of blood and cost reduction: evidence from five hospitals at different stages of implementation. Transfusion, 59(5), 1683-1691.

Tamfon, B. B., Bilounga Ndongo, C., Bataliack, S. M., Ngoufack, M. N., \& Nguefack-Tsague, G. (2020). Routine health information system in the health facilities in Yaoundé-Cameroon: assessing the gaps for strengthening. BMC Medical Informatics and Decision Making, 20(1), 1-11.

Tsang, H. C., Garcia, A., Scott, R., Lancaster, D., Geary, D., Nguyen, A. T., ... \& Pham, T. D. (2018). Streamlining a blood center and hospital transfusion service supply chain with an informatics vendor-managed inventory solution: development, implementation, and 3-month follow-up. Transfusion, 58(7), 17181725 .

Vasudev, R., Sawhney, V., Dogra, M., \& Raina, T. R. (2016). Transfusion-related adverse reactions: From institutional hemovigilance effort to National Hemovigilance program. Asian journal of transfusion science, 10(1), 31.

Wazlawick, R. (2019). Engenharia de software: conceitos e práticas. Elsevier Editora Ltda.

Webert, K. E., \& Heddle, N. M. (2017). Investigation of Acute Transfusion Reactions. Practical Transfusion Medicine, 69-80.

Williams, F., Oke, A., \& Zachary, I. (2019). Public health delivery in the information age: the role of informatics and technology. Perspectives in public health, 139(5), 236-254. 